\title{
Use of anti-citrullinated peptide and anti-RA33 antibodies in distinguishing erosive arthritis in patients with systemic lupus erythematosus and rheumatoid arthritis
}

\author{
R Mediwake, D A Isenberg, G A Schellekens, W J van Venrooij
}

\begin{abstract}
Objectives-Systemic lupus erythematosus (SLE) and rheumatoid arthritis (RA) can both present with an erosive arthritis with the small joints of the hands affected. Therefore a serological marker would be useful to distinguish between these two diseases at onset. In this study anti-RA33 antibodies, which are found in patients with SLE and RA, and anti-citrullinated peptide antibodies (anti-CCP), which have recently been described as highly specific for RA, were assessed.

Methods-Two hundred and thirty one patients receiving long term follow up for SLE were evaluated for arthritis and classified as erosive and non-erosive disease. Sixty six patients were tested for antiRA33 and anti-CCP antibodies. All the patients were tested for rheumatoid factor (RF) and HLA-DR4 status.
\end{abstract}

Results-Ten patients had erosive disease, six of whom were RF positive $(60 \%)$, and six anti-RA33 positive $(60 \%)$, whereas only two were anti-CCP positive $(20 \%)$. Two hundred and twenty one patients had nonerosive disease, 40 of whom were RF positive $(18 \%), 14$ were anti-RA33 positive $(6 \%)$, whereas only one patient was found to be anti-CCP positive $(0.5 \%)$.

Conclusion-The presence of anti-CCP antibodies may be useful in distinguishing RA from erosive SLE. Anti-RA33 antibodies and $R F$ are unhelpful.

Centre for

Rheumatologyl

Bloomsbury

Rheumatology Unit, Department of

Medicine, University

College London, UK

R Mediwake

D A Isenberg

Department of

Biochemistry,

University of

Nijmegen, The

Netherlands

G A Schellekens

W J van Venrooij

Correspondence to: Professor D A Isenberg, Bloomsbury Rheumatology Unit, Arthur Stanley House, 40-50 Tottenham Street, London W1P 9PG, UK

d.isenberg@ucl.ac.uk

Accepted for publication 4 May 2000
SLE - notably, in those with erosive disease and so called "mixed connective tissue disease". ${ }^{67}$ Antibodies recognising citrullinated peptides have been described as a marker for RA, with a specificity of $98 \%{ }^{8}$ Recent data have confirmed that these antibodies are rarely if ever present in a range of other inflammatory diseases, including scleroderma, Sjögren's syndrome, and myositis. ${ }^{8}$ In this retrospective study we have undertaken a detailed assessment of a cohort of 231 patients with SLE, some of whom have deforming arthropathy with or without erosive disease, to determine whether anti-CCP and anti-RA33 antibodies are present. In particular, we wanted to confirm the specificity of anti-CCP antibodies and to determine whether they might distinguish patients with RA from those with SLE with deforming arthropathies. As additional controls we assessed rheumatoid factor (RF) and HLA-DR4 status. The patients selected had been receiving long term follow up at the rheumatology unit at University College Hospital/The Middlesex Hospital since 1978. All patients have four or more revised criteria for the classification of SLE, ${ }^{9}$ and all those with joint pains have had hand and feet $x$ rays; those with erosions were noted. Serum samples were kept at each outpatient attendance.

Patients were classified into two main groups: those with erosive disease and those with non-erosive disease. Erosions were further classified into major (clear cut multiple erosions affecting hands and feet) or minor (small marginal erosions in one or two digits). Non-erosive disease was classified as deforming or non-deforming. Ten patients (5\%) with erosive disease were identified, of whom eight had major erosions and two had minor. Six patients $(3 \%)$ were identified with deforming non-erosive disease. Two hundred and fifteen patients had neither joint deformities nor erosions. For anti-RA33 and anti-CCP antibody assays, the 16 patients with erosive and deforming arthritis were tested, together with a further 50 control subjects from our SLE cohort with non-erosive, non-deforming arthritis, matched for age, disease duration, and ethnic mix. The patients tested were approximately $65 \%$ white subjects, $15 \%$ AfroCaribbean, $15 \%$ Asian, and 5\% other. All patients in the cohort had an RF test performed and in over 95\% the HLA-DR4 status was determined. 
Table 1 Antibody and HLA-DR4 results in the patients with systemic lupus erythematosus

\begin{tabular}{lcccc}
\hline Type of arthritis & $R F+v e$ & $\begin{array}{l}\text { Anti-RA33 } \\
+v e\end{array}$ & $\begin{array}{l}\text { Anti-CCP } \\
+v e\end{array}$ & $\begin{array}{l}\text { HLA-DR4 } \\
+v e\end{array}$ \\
\hline $\begin{array}{l}\text { Deforming major erosions } \\
\text { Deforming minor erosions }\end{array}$ & $5 / 8^{\star}$ & $6 / 8^{\star}$ & $1 / 8$ & $3 / 8$ \\
Deforming non-erosions & $3 / 6$ & $0 / 2$ & $1 / 2$ & $1 / 2$ \\
Non-deforming, non-erosive & $40 / 215$ & $0 / 6$ & $0 / 6$ & $0 / 6$ \\
\hline
\end{tabular}

${ }^{\star} \mathrm{p}<0.01$ (compared with the non-deforming, non-erosive group).

Table 2 Antibody characteristics of 10 patients with erosive systemic lupus erythematosus

\begin{tabular}{|c|c|c|c|c|c|c|}
\hline \multirow[b]{2}{*}{ Patient } & \multicolumn{2}{|c|}{$\begin{array}{l}\text { Deforming erosive } \\
\text { arthritis }\end{array}$} & \multirow[b]{2}{*}{ RF titre } & \multirow{2}{*}{$\begin{array}{l}\text { Anti-RA33 } \\
\text { status }\end{array}$} & \multirow{2}{*}{$\begin{array}{l}\text { Anti-citrulline } \\
\text { status }\end{array}$} & \multirow{2}{*}{$\begin{array}{l}\text { HLA-D } \\
\text { status }\end{array}$} \\
\hline & Minor & Major & & & & \\
\hline 1 & & Yes & $1 / 160$ & Positive & Positive & 3,4 \\
\hline 2 & & Yes & $1 / 5120$ & Positive & Negative & 3 \\
\hline 3 & & Yes & $1 / 80$ & Negative & Negative & 7 \\
\hline 4 & & Yes & $1 / 640$ & Positive & Negative & 2,7 \\
\hline 5 & & Yes & Negative & Positive & Negative & 3,4 \\
\hline 6 & & Yes & Negative & Negative & Negative & 3,4 \\
\hline 7 & & Yes & $1 / 640$ & Positive & Negative & 1,10 \\
\hline 8 & & Yes & Negative & Positive & Negative & 2,3 \\
\hline 9 & Yes & & Negative & Negative & Negative & 3,5 \\
\hline 10 & Yes & & $1 / 80$ & Negative & Positive & 1,4 \\
\hline
\end{tabular}

\section{Methods}

Anti-RA33 antibody testing was performed using immunoblotting with soluble nuclear extracts from HeLa cells, as described elsewhere. ${ }^{5}$ Sixty six patients were tested, 10 of whom had erosive disease. RF was determined by the standard slide latex test; a titre $>1 / 80$ was regarded as positive. Anti-CCP antibodies were measured in 66 patients. Anti-CCP antibodies are autoantibodies reactive with a cyclic citrullinated synthetic peptide containing the unusual amino acid, citrulline, as described. ${ }^{8}$ All HLA typing was performed by the Department of Immunology, Hammersmith Hospital London. In this study the presence or absence of HLA-DR4 was noted.

Data were analysed by $\chi^{2}$ test with Yates's correction. A p value $<0.02$ was considered to be significant.

\section{Results}

Table 1 shows the results obtained. In brief, erosive arthritis was present in 10 of the 231 patients $(4 \%)$ with SLE. Six of these 10 patients $(60 \%)$ were RF positive. Six patients $(60 \%)$ were anti-RA33 positive, and four patients were both RF and anti-RA33 positive. Only two of the 10 patients (20\%) were anti-CCP antibody positive. Table 2 shows the distribution of antibodies in these 10 patients. Both RF and anti-RA33 antibodies were often identified in the non-deforming non-erosive group, but anti-CCP antibodies were rarely found.

\section{Discussion}

RA and SLE can be difficult to distinguish in the early stages. Joint deformities in patients with SLE may resemble RA despite the far lower incidence of erosions and ligament laxity. It would be desirable to have markers that readily distinguish between these two conditions. From the present data it is clear that patients with SLE who are RF and anti-RA33 antibody positive are statistically significantly more likely to have a deforming major erosive arthritis. Therefore these serological markers do not readily distinguish between patients with RA and those with SLE with erosive arthropathy.

However, anti-CCP antibodies were found in only two of the 10 patients with SLE with erosive disease, and were most uncommon in the other patients with SLE studied. Although the presence of anti-CCP antibodies is not an absolute distinguishing feature between patients with RA and erosive SLE, their presence would appear to indicate the former diagnosis. In contrast, the presence of anti-RA33 antibodies does not distinguish RA from erosive SLE. This finding confirms the observations of Schellekens $e t a l^{8}$ that anti-CCP antibodies are virtually confined to patients with RA. In particular, anti-CCP antibodies may be used as a helpful marker to distinguish RA from SLE. Furthermore, they may prove to be particularly useful in the small group of patients with SLE with erosive disease.

It would now be of interest to undertake a prospective study of patients with early onset synovitis, to compare their RF, anti-RA33, anti-CCP antibodies, and HLA-DR4 status to determine just how effective these markers may be in determining long term outcome in patients whose initial presentation with small joint arthritis may cause some diagnostic uncertainty.

The technical assistance of BA de Jong is gratefully acknowledged. The research of G Schellekens and WJ Van Venrooij was supported by the Netherlands Foundation for Chemical supported by the Netherlands Foundation for Chemical Research (NOW-CW) with financial aid from the
Technology Foundation (STW grant 349-3149).

1 Isenberg DA, Horsfall A. Systemic lupus erythematosusadult onset. In: Maddison PJ, Isenberg DA, Woo P, Glass DN, eds. Oxford textbook of rheumatology. 2nd ed. Oxford: DN, eds. Oxford textbook of rheumatolog.
Oxford University Press, 1998:1145-8.

2 Vitali C, Bencivelli W, Isenberg DA, Smolen JS, Snaith ML, Scivto M, et al and the European Consensus Study Group For Disease Activity in SLE. Disease activity in SLE: report of the Consensus Study Group of the European Workshop for Rheumatology Research I: a descriptive analysis of lupus patients. Clin Exp Rheumatol 1992;10:527-39.

3 Alarcon-Segovia D, Abud-Mendoza C, Diaz-Jouanaen E, Igesias A, De Los Reyes V, Hernandez-Ortiz J. Deforming arthropathy of the hands in systemic lupus erythematosus. J Rheumatol 1991;18:223-9.

4 Labowitz R, Schumacher HR. Articular manifestations of systemic lupus erythematosus. Ann Intern Med 1971;74: 911-21.

5 Hassfeld W, Steiner G, Hartmuth K, Kolarz G, Scherak O, Graninger W, et al. Demonstration of a new anti-nuclear antibody (anti-RA33) that is highly specific for rheumatoid arthritis. Arthritis Rheum 1989;32:1515-20.

6 Richter Cohen M, Steiner G, Smolen JS, Isenberg DA. Erosive arthritis in systemic lupus erythematosus; analysis of a distinct clinical and serological subset. Br J Rheumatol distinct clinical

7 Isenberg DA, Steiner G, Smolen JS. Clinical utility and serological connections of anti-RA33 antibodies in systemic lupus erythematosus. J Rheumatol 1994;21:1260-3.

8 Schellekens GA, de Jong BAW, van den Hoogen FHJ. Citrulline is an essential constituent of antigenic determinants recognised by rheumatoid arthritis specific autoantibodies. J Clin Invest 1998;101:273-81.

9 Tan EM, Cohen AS, Fries JF, Masi AT, McShane DJ, Rothfield NF, et al. The revised criteria for the classification of systemic lupus erythematosus. Arthritis Rheum 1982; 25:1271-7. 